\title{
A REFORMA PSIQUIÁTRICA NO BRASIL: CONTEXTUALIZAÇÃO E REFLEXOS SOBRE O CUIDADO COM O DOENTE MENTAL NA FAMÍLIA*
}

\author{
Alda Martins Gonçalves** \\ Roseni Rosângela de Sena***
}

Gonçalves AM, Sena RR. A reforma psiquiátrica no Brasil: contextualização e reflexos sobre o cuidado com o doente mental na família. Rev Latino-am Enfermagem 2001 março; 9 (2): 48-55.

0 presente trabalho analisa as conseqüências da reforma psiquiátrica brasileira sobre o cuidado do doente mental na familia. Trata-se de um estudo descritivo-exploratório de abordagem qualitativa, cuja fundamentação teórico-metodológica foi orientada pelo materialismo histórico-dialético. Os sujeitos da pesquisa foram onze mulheres que cuidam de doente mental em família. A análise de seus discursos revelou singularidades do cuidar de um doente mental na família e as dificuldades decorrentes deste processo acentuadas pela desinstitucionalização do doente mental. Concluiu-se que a mulher, cuidadora do doente mental, cumpre um papel social importante e indispensável na consolidação da reforma psiquiátrica no país.

UNITERMOS: psiquiatria, cuidadores, relações familiares

\section{PSYCHIATRIC REFORM IN BRAZIL: CONTEXTUALIZATION AND CONSEQUENCES REGARDING THE CARE FOR THE MENTALLY ILL IN THEIR FAMILY ENVIRONMENT}

This work analyzes the consequences of the Brazilian psychiatric reform to the care provided to the mentally ill in their family environment. It is a descriptive and exploratory study based on a qualitative approach, using the historical-dialectic materialism as its theoretical and methodological framework. The subjects of the research were 11 women that provided care to mentally ill persons. The analysis of their discourses revealed unique aspects related to caring for the mentally ill in their family environment and the difficulties resulting from the process of institutionalization of the mentally ill. The conclusion is that women who provide care for the mentally ill have an important social role that is indispensable to the consolidation of the psychiatric reform in the country.

KEY WORDS: psychiatric reform, care givers

\section{LA REFORMA PSIQUIÁTRICA EN BRASIL: CONTEXTO Y REFLEJOS SOBRE EL CUIDADO CON EL ENFERMO MENTAL EN LA FAMILIA}

El presente trabajo analiza las consecuencias de la reforma psiquátrica basileña sobre el cuidado del enfermo mental en la familia. Se trata de un estudio descriptivo-exploratorio de abordaje cualitativo, cuya fundamentación teórico-metodológica fue orientada por el materialismo histórico-dialéctico. Los sujetos de la investigación fueron once mujeres cuidadoras de enfermos mentales. El análisis de sus discursos reveló las singularidades del cuidar de un enfermo mental. Se concluye que la mujer cuidadora del enfermo mental cumple un papel social importante e indispensable en la consolidación de la reforma psiquiátrica en el país.

TÉRMINOS CLAVES: reforma psiquiátrica, cuidadores

\footnotetext{
* Este trabalho é parte de uma pesquisa realizada para elaboração da dissertação de mestrado: "A mulher que cuida do doente mental em família"

** Professor da Escola de Enfermagem da UFMG, Mestre em Enfermagem. Endereço: Escola de Enfermagem da Universidade Federal de Minas Gerais - Av. Alfredo Balena, 190 - 30190-100 - Belo Horizonte - Minas Gerais - Brasil

*** Professor da Escola de Enfermagem da UFMG, Doutora em Enfermagem; orientadora da dissertação, pesquisadora CNPq
} 
INTRODUÇÃO

$\boldsymbol{E}_{\text {ste estudo é produto de uma pesquisa: "A mulher que }}$ cuida do doente mental em família". Tem por objetivo analisar as conseqüências da reforma psiquiátrica brasileira sobre o cuidado do doente mental na família. Trata-se de um estudo qualitativo, tendo no materialismo histórico-dialético o caminho teórico-metodológico. Acredita-se que as consequências da reforma psiquiátrica refletem de forma direta sobre a família do doente mental, principalmente sobre as pessoas responsáveis pelo cuidado.

A opção teórico-metodológica foi assumida na crença e no ato consciente de que a pesquisa social no campo da saúde, sob o enfoque dialético, não depende apenas do conhecimento técnico. Definiu-se, assim, uma postura intelectual, uma visão social da realidade e uma prática capazes de irem além dos fatos e das verdades contidas nos esquemas abstratos de determinações gerais exigindo o rompimento com a ideologia dominante ${ }^{(1-2)}$. 0 pensamento dialético é aquele que leva ao questionamento e à transformação do social ${ }^{(3)}$. Com base nesta compreensão, foram analisadas algumas das conseqüências da reforma psiquiátrica brasileira sobre o cuidar do doente mental na família.

Neste estudo, o termo "doença mental" é usado por falta de outra expressão que sintetize a idéia de doença ainda prevalecente, e que, ao mesmo tempo, traduza a noção de "existência sofrimento do sujeito em relação ao corpo social" como é a proposta alternativa feita pela psiquiatria democrática italiana, bem como a de "sofrimento psíquico", usada, atualmente, por muitos autores que, contudo, não deixam de usar também o termo "doença mental".

0 cuidado não institucionalizado é uma prática milenarmente assumida por mulheres ${ }^{(4)}$. Quanto ao cuidado do doente mental, esta tarefa também vem sendo atribuída às mulheres ${ }^{(5-6)}$

Os sujeitos desta pesquisa constituíram-se de onze mulheres, cuidadoras de doentes mentais contactadas aleatoriamente em serviços de saúde mental, no momento em que realizavam uma das tarefas de cuidado, ou seja, no momento em que acompanhavam o doente mental. Esses serviços foram: um hospital e ambulatório da rede privada; um serviço de urgência de um hospital público e um centro de referência em saúde mental (CERSAM), também serviço público, todos do município de Belo Horizonte - Minas Gerais. Após orientação sobre objetivos, finalidades e sigilo na condução do trabalho, em cumprimento à Resolução 196/96 sobre pesquisa envolvendo seres humanos, as cuidadoras consentiram livremente em serem visitadas e entrevistadas em seus domicílios.

0 instrumento utilizado na coleta de dados foi a entrevista semi-estruturada, gravada e transcrita. Considerou-se suficiente 0 número de entrevistas quando percebeu-se a saturação das informações.

Para se realizar a análise dos dados, optou-se pela utilização da técnica de análise de discurso ${ }^{(7-8)}$. Cada entrevista foi lida três vezes procedendo-se à identificação de figuras e frases temáticas, o que levou a construção dos temas. As falas foram identificadas por letras e números, de acordo com um código estabelecido para a pesquisa e os nomes das pessoas foram atribuídos hipoteticamente.

\section{SOBRE A HISTÓRIA DA LOUCURA}

0 conhecimento sobre a historicidade dos fatos e fenômenos sociais é o caminho para explicitar as contradições e determinações presentes na trajetória da humanidade.

0 enfoque da loucura como doença e da psiquiatria como especialidade médica é recente na história da humanidade aproximadamente 200 anos. A partir do século XVIII é que, o homem inventou uma nova maneira de se perceber, uma nova maneira de vivenciar a condição humana ${ }^{(9)}$.

A loucura sempre existiu, bem como o lugar para se tratar dos loucos: templos, domicílios e instituições, mas a instituição psiquiátrica, propriamente dita, é uma construção do século XVIII ${ }^{(10)}$.

A partir dessa nova forma de vivenciar a condição humana, estabeleceu-se "o diferente", aquele que não segue o padrão de comportamento que a sociedade define. 0 doente mental, o excluído do convívio dos iguais, dos ditos normais, foi então afastado dos donos da razão, dos produtivos e dos que não ameaçavam a sociedade.

Tratar do doente mental foi então sinal de exclusão, de reclusão e asilamento. Hoje, esta realidade ainda existe, porém de forma mais consciente e menos exclusiva. Por não se admitir a exclusão, corre-se o risco de não se admitir a diferença. Esta não pode ser negada, é necessário reconhecê-la e conviver com ela sem ter que excluir, conforme a grande aspiração da reforma psiquiátrica.

\section{ELEMENTOS PARA CONTEXTUALIZAR A REFORMA PSIQUIÁTRICA NO BRASIL}

A reforma psiquiátrica no Brasil é um movimento histórico de caráter político, social e econômico influenciado pela ideologia de grupos dominantes. A práxis da reforma psiquiátrica faz parte do cotidiano de um bom número de profissionais de saúde mental. 
Tem como uma das vertentes principais a desinstitucionalização com conseqüente desconstrução do manicômio e dos paradigmas que o sustentam. A substituição progressiva dos manicômios por outras práticas terapêuticas e a cidadania do doente mental vêm sendo objeto de discussão não só entre os profissionais de saúde, mas também em toda a sociedade.

0 modelo de assistência psiquiátrica ainda predominante no Brasil, com base na legislação de 1934, propõe, fundamentalmente, a hospitalização e o asilamento do doente mental, visando atender, sobretudo, a segurança da ordem e da moral pública. Embora predominante, este modelo é atualmente considerado falido e sua base ideológica, desmistificada ${ }^{(11)}$.

Um novo modelo vem sendo edificado a partir da contribuição de vários segmentos da sociedade e implica a desconstrução literal do modelo hegemônico. A reforma psiquiátrica vem se desenvolvendo no Brasil há várias décadas, mais precisamente a partir do final dos anos setenta. 0 movimento aponta as inconveniências do modelo que fundamentou os paradigmas da psiquiatria clássica e tornou o hospital psiquiátrico a única alternativa de tratamento, facilitando a cronicidade e a exclusão dos doentes mentais em todo o país.

A reforma psiquiátrica, hoje defendida, é fruto de maior maturidade teórica e política, alcançada ao longo das últimas décadas, com maior conscientização da sociedade civil $\operatorname{organizada}^{(12)}$.

No percurso da reforma psiquiátrica brasileira, houve um momento em que as denúncias sobre a precariedade da assistência psiquiátrica desencadearam estudos e trouxeram a público dados e informações de órgãos públicos como, por exemplo, do Ministério da Saúde, antes não valorizados, tais como número de leitos, custos e qualidade da assistência. Os dados do Centro de Informações de Saúde, do Ministério da Saúde, revelaram que em 1988, o número de leitos psiquiátricos representava $19,1 \%$ do total de leitos disponíveis em todo o país, percentual superado apenas pelos leitos de clínica médica, $21,6 \%^{(13)}$.

A reforma psiquiátrica, hoje, é discutida como parte das políticas de saúde, principalmente no âmbito dos governos municipais. Na esfera federal, o Projeto de Lei 3.657, de 1989 ${ }^{(14)}$, depois de aprovado na Câmara dos Deputados em 1991, tramitou no Senado, e só em janeiro de 1999, foi aprovado um projeto substitutivo. A matéria deverá voltar à Câmara para aprovação final ${ }^{(15)}$. A versão atual dispõe sobre a proteção e os direitos das pessoas portadoras de transtornos psíquicos e redireciona o modelo assistencial de saúde mental. Nesta versão, há algumas possíveis aberturas que, no futuro, poderão facilitar mecanismos de criação, contratação ou financiamento de leitos psiquiátricos com orçamentos públicos (artigo $4^{\circ}$ ), bem como de internação em instituições com características asilares (artigo $5^{\circ}, \S 3^{\circ}$ ). 0 projeto de Lei 3.657 cumpriu um importante papel que foi o de trazer para o debate a realidade da assistência psiquiátrica brasileira e suscitar decisões importantes para a consolidação da reforma psiquiátrica no país.

A reforma psiquiátrica, tomando como desafio a desinstitucionalização, tem sido discutida e entendida com uma certa variedade de conceitos e conseqüências.

Segundo o conceito defendido pela reforma, a desinstitucionalização não se restringe à substituição do hospital por um aparato de cuidados externos envolvendo prioritariamente questões de caráter técnico-administrativo-assistencial como a aplicação de recursos na criação de serviços substitutivos. Envolve questões do campo jurídico-político e sociocultural. Exige que, de fato haja um deslocamento das práticas psiquiátricas para práticas de cuidado realizadas na comunidade.

A questão crucial da desinstitucionalização é ${ }^{(16)}$ uma "progressiva 'devolução à comunidade' da responsabilidade em relação aos seus doentes e aos seus conflitos".

Para outro autor ${ }^{(17)}$, trata-se de buscar "outro lugar social para a loucura na nossa cultura". Assim, a indagação sobre um outro lugar para a loucura põe em debate outro pólo da questão: a cidadania do doente mental.

Há necessidade de distinguir nos projetos da reforma a maneira como lidam com a desinstitucionalizaçãa ${ }^{(12)}$. 0 conceito de desinstitucionalização vem sofrendo uma verdadeira metamorfose, abrindo novas possibilidades para o campo da reforma psiquiátrica. 0 termo desistitucionalização vem sendo compreendido por diferentes atores como desospitalização, desassistência ou desconstrução, conforme interesses ou pontos de vista impregnados de poder ideológico.

Publicações recentes têm sido dedicadas ao tema. Vale lembrar aqui a opinião de vários autores ${ }^{(6,12,18-19)}$ que alertam quanto aos riscos e quanto a ideologia impregnada na noção de desinstitucionalização entendida como desospitalização ou, até mesmo, como desassistência. Essa concepção acaba por representar os interesses neoliberais do Estado empenhado na racionalização financeira.

\section{REFLEXOS DA REFORMA PSIQUIÁTRICA SOBRE 0 CUIDADO COM DOENTES MENTAIS NA FAMÍLIA}

A reforma psiquiátrica no Brasil vem configurando-se como um movimento com diferentes graus de adesão e entendimento por parte dos profissionais e de alguns segmentos da sociedade. Tratada como desospitalização, sem as condições necessárias para viabilizar uma proposta de ressocialização/reabilitação, reflete de forma 
negativa sobre a família, pois é nesta que se dá o embate com a realidade cotidiana do cuidado ao doente mental atribuído às mulheres.

Está contido na reforma psiquiátrica um novo protocolo na relação da sociedade com os cidadãos pertencentes a aqueles grupos de segregados $^{(6)}$ :

“...enquanto a sociedade não dispõe de equipamentos sociais para a assistência e cuidados dos egressos das instituições ou daqueles que não chegaram a ser encaminhados para elas, grande parte da tarefa de cuidados desses pacientes fica cometida às mulheres, 0 que abre uma questão não desprezível para a discussão".

0 que se espera da reforma psiquiátrica não é simplesmente a transferência do doente mental para fora dos muros do hospital, "confinando-o" à vida em casa, aos cuidados de quem puder assisti-lo ou entregue à própria sorte. Espera-se, muito mais, o resgate ou o estabelecimento da cidadania do doente mental, o respeito a sua singularidade e subjetividade, tornando-o sujeito de seu próprio tratamento sem a idéia de cura como o único horizonte. Espera-se, assim, a autonomia e a reintegração do sujeito à família e à sociedade.

Outros autores, referem-se à família para aludir ao fato da crescente intolerância para com o doente mental. Essa intolerância é conseqüência de uma mudança de atitude das pessoas, própria das sociedades capitalistas avançadas e em áreas mais industrializadas de países como o Brasil. Estas mudanças refletem em nível, individual, familiar e institucional, o fato de essas sociedades serem cada vez mais incapazes de acomodar o "desviante", o "diferente" (20-21)

Na literatura brasileira sobre saúde mental, os autores freqüentemente se referem à necessidade de assistência à família do doente mental como parte ou estratégia do tratamento. Entretanto não são freqüentes as discussões e trabalhos que demonstrem um conhecimento contextualizado de como e por quem os doentes mentais são cuidados fora dos espaços institucionais da psiquiatria, ou seja, na família.

Vários estudos ${ }^{(18-19,22-24)}$, têm chamado a atenção sobre sobrecarga que a família enfrenta na convivência com o doente mental, principalmente por ocasião da alta hospitalar, desencadeando atitudes de incompreensão familiar e até de rejeição, motivadoras de reinternações sucessivas ou de internações permanentes. Defendem que a família necessita de ajuda de profissionais da saúde mental.

Sabe-se, no entanto, que na prática, o grupo como um todo, dificilmente está disponível e/ou disposto a trabalhar a dimensão subjetiva e objetiva do cuidado com o doente mental. É comum profissionais da saúde mental exigirem que a família aceite a doença sem oferecer-lhe suporte e orientações ${ }^{(24)}$.
A instituição familiar não se mostra favorável a respeito da desinstitucionalização do doente mental exercendo pressão para que a instituição psiquiátrica continue "a manter a custódia dos pacientes porque esse pesado encargo não é aceito passivamente por ela" ${ }^{(19)}$.

Os diferentes percursos da reforma psiquiátrica brasileira têm evidenciado a fragilidade do sistema de saúde para oferecer outro tipo de atendimento que não aquele centrado no leito hospitalar. Evidencia-se, também, a tendência dos órgãos formadores em manter a doença mental como um fenômeno biológico ou um "desvio" sobre os quais o profissional sabe e pode intervir a despeito da singularidade e subjetividade do sujeito/doente mental, do sujeito/ família e do sujeito/comunidade. Também não são valorizadas as múltiplas determinações sociais, econômicas, políticas, culturais e religiosas, individuais e coletivas.

Se não é mais aceitável estigmatizar, excluir e recluir os loucos, também não se pode reduzir a reforma psiquiátrica à devolução destes às famílias, como se estas fossem, indistintamente, capazes de resolver a problemática da vida cotidiana acrescida das dificuldades geradas pela convivência, pela manutenção e pelo cuidado com o doente mental.

Isto implica uma progressiva mudança de mentalidade e comportamento da sociedade para com o doente mental. Exige revisões das práticas de saúde mental em todos os níveis e posturas mais críticas dos órgãos formadores de profissionais, principalmente, os da saúde e da educação.

\section{A VOZ DE MULHERES CUIDADORAS DE DOENTES MENTAIS NA FAMÍLIA}

A partir de pesquisas com mulheres cuidadoras de doentes mentais em família, pode-se inferir que a mulher é a principal atora com a qual deve-se estabelecer aliança, para consolidar a reforma psiquiátrica $^{(5-6)}$.

Os resultados do presente estudo permitiram o desvelamento de uma realidade que, dentre outras, evidenciou os reflexos sobre o cuidado com o doente mental na família, no contexto da reforma psiquiátrica brasileira, a partir da concepção das mulheres/cuidadoras entrevistadas.

Um recorte da história e do viver cotidiano das onze cuidadoras, no fazer e refazer de cada ação própria do cuidar de um doente mental na família, revelou a dimensão singular desse cuidar. Essa dimensão articula-se à dimensão global que perpassa o social, o econômico e todas as formas político-ideológicas derivadas. A dimensão particular, onde estabelecem as relações próprias do processo de cuidar do doente mental na família, aparece 
intermediando as dimensões geral e singular. Estas relações ocorrem entre a cuidadora, a família, os serviços de saúde mental e a comunidade.

Na dinâmica dessas relações os reflexos da reforma psiquiátrica sobre o cuidado do doente mental na família revelam dificuldades de ordem emocional, social, relacional, econômica e materiais, conforme expressaram as próprias cuidadoras:

Eles (o pessoal do serviço de saúde) não vem aqui vê onde que eu moro. Acha que eu tenho que dá conta... Quando ela foge, eles briga é comigo ...Eu não tenho culpa dela fugi, batê nos outros na rua, ficá sumida, mendigando (CO7).

Ao se referirem à vida dos doentes mentais, as cuidadoras falaram sobre o comportamento agressivo e violento deles e as conseqüências desse comportamento na convivência familiar:

...Laura não pode ficar com mãe, agride ela, morde, senta o pau, e mãe não dá conta de defendê. Eu não posso sair pra nada quando ela tá em casa. Trabaiá, passeá, namorá... eu já não sei mais o que é isso (CO7).

Ele já tentou várias vezes me matá e até matá minha neta de três anos, enforcada. Tentou matá minha filha também, jogou uma barra de ferro nela.

...aí ele quebrou tudo, eu fiquei três anos sem podê fazê o barracão. Cadê que ele melhorava! (A03).

A visão das cuidadoras sobre o comportamento agressivo e violento de seus doentes mentais não expressou rejeição a eles. 0 tom de suas vozes e a expressão de seus rostos, no momento em que falavam, denotavam sofrimento. Os enunciados, confirmam tratar-se de um comportamento com características doentias e expressam a idéia de periculosidade que, de um modo geral, se atribui ao doente mental.

0 comportamento suicida é percebido pelas cuidadoras como um processo complexo e delicado na relação cuidadora/doente mental. Elas buscam compreender, sentem-se impotentes para tomar atitudes ou agem no sentido de evitar que o doente mental chegue ao desfecho das tentativas de suicídio.

Orlando sempre falou em suicidar-se. Ele diz que tem medo de me perder e ter que depender do irmão (choro) (A01).

Quando a crise se instala, não tem jeito, não tem como tratar em casa. Corre o risco de tentativa de suicídio. Isto é perigoso, uma coisa que eu não quero que aconteça, acredito que nem ele, é involuntário (D11).

Mário não quer se tratar, não quer deixar a bebida. Bebe até quase morrer (A02).

Esses discursos revelam que a tentativa de suicídio e a convivência com a manifestação do desejo de morrer são situações limites, nas quais as cuidadoras não podem prescindir de um suporte de atendimento, muitas vezes de emergência.

Percebeu-se da experiência das cuidadoras que às mulheres está sendo transferida a tarefa árdua de cuidar dos pacientes desospitalizados ${ }^{(6)}$.
As cuidadoras expressaram que os momentos de maior pico das tensões eclodem nas chamadas crises dos doentes mentais, sejam com manifestações de tentativa de suicídio ou não. 0 momento de uma recidiva ou do agravamento do estado mental de um doente, torna-se muito perturbador para as famílias e, especialmente, para as cuidadoras, frente às dificuldades que elas têm para compreender e para evitar um desfecho desastroso da crise.

A análise dos discursos das cuidadoras revelou a multiplicidade de problemas, ansiedades, medos e tristezas que elas vivem freqüentemente durante as crises de seus doentes mentais: Quando ele está em crise, fica fechando as portas e dizendo que a polícia está atrás dele. Ninguém tem sossego dentro de casa. É aquilo o dia inteiro. Tenho que perder aula pra ficar com ele e não consigo estudar nada (B04). Nesta última crise, Orlando mudou os hábitos de alimentar, não tomou o remédio, isolou-se no quarto, passou a desenhar sem parar usando as duas mãos ao mesmo tempo. Punha músicas clássicas no computador o tempo todo. Não falava com ninguém. Aí foi só piorando. A única saída foi internar (A01).

Quando não quer tomar o remédio, tem que levá ele pra interná. Desta vez ele pegou a falá comigo assim: nós vai fazê um quebra pau. Eu ia matá ele e ele ia me matá. Então foi onde que saí e fui pra casa de minha filha... que eu não tô mais dando conta. Quando ele faz assim, ele vem com qualquer coisa pra cima da gente (A03).

Outra situação penosa para as famílias administrarem e aceitarem é a improdutividade dos seus doentes mentais pelo que representa social e economicamente. A manutenção de um membro improdutivo na família pesa no orçamento, principalmente quando a renda familiar é muito baixa. Estudando famílias de esquizofrênicos, concluiu-se que há três tipos de sobrecarga: a financeira, o desenvolvimento das rotinas familiares e as manifestações de doença física e emocional ${ }^{(24)}$.

Numa sociedade competitiva, sob a égide do modo de produção capitalista, aquele que não produz, não tem rendas e, além disso, carrega o estigma de ser doente mental, não tem inserção social. Então passa a ser visto como ocioso, improdutivo, inútil, sem cidadania.

Algumas falas expressaram a dimensão do sofrimento, tensões e conflitos mediados pelas cuidadoras diante da improdutividade de seus doentes mentais:

A mulher e os filhos dele humilharam ele, abandonaram. Tudo porque ele não tem mais condição de trabalhar. Pra eles o pai valia enquanto tava ganhando dinheiro e construindo a casa que eles moram (CO6).

Mário nunca chega em casa com dinheiro. A gente dá comida, dá roupa, calçado.... Se eu deixá, ele anda feito um mendigo.

...Os irmãos dele não admite que ele não trabalhe (A02).

Laura gosta mesmo é de ficar em casa comendo, bebendo e dormindo, não ajuda a fazer nada (C07).

Os discursos das cuidadoras foram reveladores de uma 
concepção veiculada na sociedade em geral, sobre a doença mental, que reforça a idéia de periculosidade, de incapacidade e de que 0 saber médico é definidor do destino dos doentes mentais. Exemplo dessa concepção são as explicações atribuídas pelas cuidadoras para a doença, ou para o seu agravamento.

Quando ele tá em casa eu preocupo com as brigas com os irmãos, quando tá na rua eu não sei o que pode acontecer com ele (A02).

Ele não tem condições de tomar os remédios sozinho. A gente é que tem que dar ele na mão, senão ele toma tudo de uma vez.

Os médico já disse que não tem jeito. Que é porque o cérebro dele está todo estragado, tá mole. Por isso que ele fica agressivo, não sabe o quê qui tá fazendo. Aí a gente fica preocupada porque o pobrema é que ele qué matá a gente(AO3).

Ele piorou muito quando eu fiquei doente e tive que ficá internada. $0 \mathrm{irmão}$ mais velho magoou e maltratou ele muito (A05).

A percepção das cuidadoras quanto ao tratamento dos seus doentes mentais é condizente com o que, de fato, mais acontece: tratamento sob a forma de medicação para conter 0 comportamento e tornar o doente mais adaptado ao seu contexto social. Não há, na realidade da maioria das famílias, alternativas de tratamento para que possam racionalizar o uso da medicação e diminuir os seus efeitos indesejáveis.

Os discursos das cuidadoras confirmam os achados ${ }^{(19)}$ que os familiares exigem para "agüentarem" os doentes em casa, que o comportamento deles esteja controlado através da medicação.

Algumas cuidadoras assim se expressaram:

Tomando os remédios direitinho, Eva fica bem boa. Sem eles vai piorando, aí vira uma peleja (F08).

Quando Adenir sai do hospital fica bom, até uns dois meses, se ele tomar os remédios direitinho (A05).

Quando os remédios vai acabando, Joel começa a não dormir. Aí, é ficar só piorando (A03).

0 que as cuidadoras pensam sobre a reabilitação ou a cura de seus doentes mentais? A análise dos discursos permitiu apreender que há esperança na reabilitação ou mesmo na cura, ainda que, por vezes, desânimo e incerteza:

Incentivo ele para estudar... Ele pode. Ele é inteligente...(A01).

Eu acho que ele pode ficar bom. Quero abrir um comerciozinho pra ele, quero que ele faça um curso de mecânica... Ele tem vontade de ter um carro, de dirigir, de estudar e trabalhar (A05).

Eu tenho esperança de ver ele fora disso. É uma esperança que tá dentro de mim, não dentro dele... tem hora que eu desanimo, tem hora que eu vou pra frente(A02).

Eu espero que um dia ela, sarava, né? Mais pelo jeito, parece que tá ficando é pior (CO7).

A idéia de reabilitação ou "reintegração" (25) não deve ser entendida como uma adaptação do doente mental a um determinado padrão de normalidade, mas sim como "reintegrar-se a si próprio e à rede intersubjetiva", possibilitando ao sujeito o sentimento de "estar no mundo".

As expectativas que as cuidadoras revelaram ter com relação aos seus doentes mentais são, por vezes, extremamente otimistas. Suscitam muito mais um desejo de cura, que pode não encontrar respaldo na realidade concreta. Por isso, acredita-se que elas devam ser acompanhadas e orientadas quanto às reais possibilidades de reabilitação e cura dos doentes mentais.

Observa-se ${ }^{(25)}$ que a emancipação do sujeito e o emergir da capacidade de gerenciar sua própria vida se dá em graus diferentes para alguns e, talvez, possa não acontecer para todos.

Cuidadoras cujas condições materiais são muito precárias, aliadas a um comportamento do doente mental bastante inadequado, com atitudes de violência, auto-agressividade e heteroagressividade ou com uma grande intolerância dos familiares e da comunidade, mostram maior grau de rejeição ao doente mental, manifestando o desejo de que seus doentes fiquem internados de forma permanente.

Os seguintes trechos de entrevistas são esclarecedores dessa análise.

Eu já tentei muito eles levá a Laura pra um hospital pra ela ficá definitivo, mais eu sei que é difíicil. Eles diz que precisava ela tá muito pior (C07). As fôias lá do hospital (...) tem tudo escrito, eu interno o Joel lá desde que ele tinha 18 anos. Já cunversei com eles, mais eu sei que se dependê daquela assistente social, ele não vai. É sujeito uma hora ele me matá ou a polícia matá ele.

Os vizinhos já fez abaixo assinado pra levá ele. Tem um policial aí, que conhece ele de muito tempo que já falô que lugar dele é num hospital definitivo. Só que o hospital não dá apoio (A03).

Na verdade, os serviços de saúde, muitas vezes, trabalham com a idéia de uma família idealizada. Este fato é denunciado ${ }^{(6)}$ quando se afirma que: "...as condições da família para ficar com o paciente não são explicitadas. Parte-se na maioria das vezes, da idéia de que a família, porque é família tem essa condição".

Outras cuidadoras manifestaram que a internação é o último recurso de que lançam mão, quando seus doentes estão em crise, mas que não podem prescindir desse recurso.

Quando Orlando não está bom, fico mais em casa; aviso que não vou ao escritório. Só interno quando ele fica muito alterado, agredindo os vizinhos, os empregados da fábrica e o meu motorista (A01).

O governo precisa rever esta tendência de acabar com os hospitais. É preciso ver também o lado dos familias.

O tratamento nos hospitais psiquiátricos é válido. Quantas vezes o Pedro se internou e voltou bom. Há um limite que a família não suporta, não tem como, não tem estrutura (D11).

Para mim, interná o Adenir é muito sofrimento. A irmã dele acha que tenho de deixá só internado. A vida toda!...de jeito nenhum ! (fala com emoção) (A05). 
Ela agora tava no CERSAM, mas agora não teve jeito. Esta foi a primeira vez que ela ficou internada em hospital psiquiátrico (A10).

A superação das contradições presentes no imaginário e no concreto das cuidadoras acerca das concepções sobre a doença, o tratamento, a reabilitação e a cura, bem como sobre a internação e os serviços de saúde mental, significa um processo de revisão e reconstrução do conceito de "ser" e "estar" doente mental. A revisão e a reconstrução deste conceito implicam uma mudança de postura por parte de toda a sociedade inventando e recriando novas formas de cuidar do doente mental.

\section{CONSIDERAÇÕES FINAIS}

A realização deste estudo permitiu apreender que 0 fenômeno em transformação ocorre sob a égide de um processo dialético que não avança, de forma automática, como um destino. As mudanças ocorridas na realidade social, política, econômica e cultural que hoje impulsionam a reforma psiquiátrica não se deram ao acaso, senão com um movimento de revolução e transformação com repercussões na vida do doente mental, de sua família e na sociedade. Não há mais possibilidade de um recuo deste movimento, pois trata-se de um processo social, histórico e dinâmico que já alcançou o sentido do novo. A negação do manicômio já convive com a sua antítese. A síntese - os serviços substitutos - já é uma realidade e exige a criação de novas formas de cuidar, tendo a mulher cuidadora como a protagonista principal deste cenário.

0 rompimento com o saber/fazer tradicional da psiquiatria e a construção de um novo saber/fazer baseado nos princípios éticopolíticos do doente mental como cidadão, são metas da reforma psiquiátrica.

\section{REFERÊNCIAS BIBLIOGRÁFICAS}

1. Frigotto G. 0 enfoque da dialética materialista histórica na pesquisa educacional. In: Fazenda I, Masini EFS. Metodologia da pesquisa educacional. São Paulo: Cortez; 1989. p. 69-90.

2. Minayo MCS. 0 desafio do conhecimento - pesquisa qualitativa em saúde. $5^{a}$ ed. São Paulo: HUCITEC/ABRASCO; 1998.

3. Gonçalves FS. Vida, trabalho e conhecimento. [tese]. São Paulo (SP): Faculdade de Educação/USP; 1995.

4. Collière MF. Promovendo a vida - da prática das mulheres de virtude aos cuidados de enfermagem. Lisboa: Printipo Indústrias Gráficas; 1989.

5. Gonçalves AM. A mulher que cuida do doente mental em família. [dissertação]. Belo Horizonte (MG): Escola de Enfermagem/UFMG; 1999.
A ocorrência de uma contradição importante entre as propostas da reforma psiquiátrica e a devolução ou manutenção do doente mental na família pôde ser confirmada. 0 doente mental está sendo entregue à família sem o devido conhecimento das reais necessidades e condições da família, especialmente das cuidadoras em termos materiais, psicossociais, de saúde e qualidade de vida, aspectos estes profundamente interligados.

Apreendeu-se do discurso das mulheres cuidadoras de doentes mentais na família, que a desinstitucionalização/ desassistência é duplamente perversa porque atinge principalmente o doente mental e a elas próprias, todos fragilizados pela condição de não aceitos socialmente e pelos reveses que a realidade thes impõe.

Sendo a desinstitucionalização parte do cuidado a que 0 doente mental tem direito, e sendo este cuidado um processo ético porque contrário à estigmatização, à exclusão, à violência, entendeuse, a partir, dos discursos das cuidadoras, que esse mesmo processo ético deve ser estendido também a elas, que sofrem estas mesmas conseqüências ao terem que cuidar de pessoas, rejeitadas pela sociedade.

Espera-se que a superação das contradições impulsione um progressivo movimento de transformação da práxis dos profissionais da saúde e dentre estes especialmente a enfermeira/ o enfermeiro de saúde mental para que se alie à mulher que cuida do doente mental em família ajudando-a no cuidado de si e dos doentes mentais.

0 desafio está lançado. É preciso coragem, competência, audácia e ciência. É preciso arte, interdisciplinaridade e espírito de união para enfrentar o cuidado ao doente mental e à sua cuidadora, porque o cuidado destes se faz no cotidiano de suas vidas, na práxis, no encontro com a diferença - "a loucura dos loucos pela vida".

6. Ornellas CP. 0 paciente excluído: história e críticas das práticas médicas de confinamento. Rio de Janeiro: Revan; 1997.

7. Fiorin JL. Linguagem e ideologia. $6^{a}$ ed. São Paulo: Ática; 1998. 8. Fiorin JL, Savioli FP. Para entender o texto - leitura e redação. $13^{\text {a }}$ ed. São Paulo: Ática; 1997.

9. Bezerra BJr. Saúde mental ou psiquiatria. Anais do $4^{\circ}$ Encontro de Pesquisadores em Saúde Mental e $3^{\circ}$ Encontro de Especialistas em Enfermagem Psiquiátrica; 1995; Ribeirão Preto; SP. Ribeirão Preto: EERP-USP; 1995.

10. Foucault M. A história da loucura na Idade Clássica. $2^{\mathrm{a}}$ ed. São Paulo: Perspectiva; 1978.

11. Moura FDM Neto. Bases para uma reforma psiquiátrica. In: Marsiglia R, Dalari D, Costa JF. Saúde mental e cidadania. São Paulo: Mandacarú; 1987. p. 57-65.

12. Amarante P. 0 homem e a serpente: outras histórias para loucura e a psiquiatria. Rio de Janeiro: FIOCRUZ; 1996. 
13. Alves DSN et al. Elementos para uma análise da assistência em saúde mental no Brasil. Seminário Nacional de Enfermagem em Saúde Mental. São Paulo: Escola de Enfermagem-USP; 1994.

14. Câmara dos Deputados (BR). Projeto de lei n 3657-1989. Dispõe sobre a extinção progressiva dos manicômios e sua substituição por outros recursos assistenciais e regulamenta a internação psiquiátrica compulsória. Brasília: CD; 1991.

15. Senado Federal (BR). Projeto de lei substitutivo ao projeto $n^{0}$ 3657-1989; Dispõe sobre a proteção e os direitos das pessoas portadoras de transtornos psíquicos e redireciona o modelo assistencial em saúde mental. Brasília: SF; 1999.

16. Delgado PGG. Perspectivas da psiquiatria pós-asilar no Brasil (como um apêndice sobre a questão dos cronificados). In: Tundis SA, Costa NR, organizadores. Cidadania e loucura: políticas de saúde mental no Brasil. Petrópolis: Vozes/ABRASCO; 1987.

17. Birman JA. Cidadania tresloucada. In: Bezerra Amarante P, organizadores. Psiquiatria sem hospício: contribuição ao estudo da reforma psiquiátrica. Rio de Janeiro: Relume-Dumará; 1992. p. 7190.

18. Morgado A, Lima LA. Desinstitucionalização: suas bases e a experiência internacional. J Bras Psiquiatr 1994; 43(1): 19-28.
19. Sadigursky D. Desinstitucionalização do doente mental: expectativas da família. [tese]. Ribeirão Preto (SP): Escola de Enfermagem de Ribeirão Preto/USP; 1997.

20. Resende H. Saúde mental: prioridade de saúde pública? A Saúde no Brasil 1983; 3(1): 140-5.

21. Carvalho GG. Ressocialização/reabilitação ocupacional em saúde mental. J Bras Psiquiatr 1989; 4(38): 242-6.

22. Carmo DR. Contribuição ao estudo da integração na família de pacientes egressos de hospitais psiquiátricos. [dissertação]. Ribeirão Preto (SP): Escola de Enfermagem de Ribeirão Preto/USP; 1981. 23. Sgambatti ERV. Reinternação e rejeição familiar: um estudo com pacientes psiquiátricos. [dissertação]. Ribeirão Preto (SP): Escola de Enfermagem de Ribeirão Preto/USP; 1983.

24. Koga M. Convivência com a pessoa esquizofrênica: sobrecarga familiar. [dissertação]. Ribeirão Preto (SP): Escola de Enfermagem de Ribeirão Preto/USP; 1997.

25. Delgado S. CAPS Rubens Corrêa - A construção de uma clínica diferenciada. In: Venâncio AT, Leal EM, Delgado PG, organizadores. 0 campo da atenção psicossocial. Rio de Janeiro: IFB-Te Corá; 1997. p.114-8. 